\title{
Production Capacity Allocation Optimization
}

\author{
Sadik Çökelez
}

\begin{abstract}
This paper aims at developing a production model capable of determining the optimal production levels affected by production process and type of production capacity utilized such as regular capacity, overtime capacity, and subcontracting. The linear programming model developed for this purpose also involves a distribution component for the manufactured products in question.
\end{abstract}

Key words--- production allocation optimization, logistics, linear programming model

\section{INTRODUCTION}

$\mathrm{T}$ HE production model in this study is useful finding the optimal production amounts for multiple products. The multiple production processes and different types of production capacities such as regular capacity,overtime capacity and subcontracting are taken into account. The model integrates several components as done in a previous work[1]; however, the model orientation and emphasis are quite different. The objective function of the linear program consists of returns on production, costs on production depending on the process and the capacity type, and distribution of the the optimal amounts manufactured. Capacity constraints, distribution and demand constraints follow the objective function of the optimization model..

\section{THE Model DesigN}

Prior to designing the linear programming optimization mode, 1 the suitable notations and definitions used in the model are presented below followed by the explanation of components that utilize these notations. Let:

$\mathrm{R}_{\mathrm{ijk}}=$ unit return on product $i$ produced by process $j$ and capacity type $k$ such as regular production capacity, overtime production capacity or subcontracting

$\mathrm{C}_{\mathrm{ijk}}=$ unit cost of production for product $i$ produced by process $j$ and capacity type $k$ such as regular production capacity, overtime production capacity or subcontracting

$\mathrm{D}_{\mathrm{ijkq}}=$ unit cost of shipment for product $i$ produced by process $j$ and capacity type $k$ such as regular production capacity, overtime production capacity or subcontracting to demand center $q$

Prof. Dr. Sadık Çökelez works at Dept. of Econometrics, I.I.B.F, Süleyman Demirel University, Isparta, Turkey

Phone: (90)537-790-7927 E-mail:scokelez2@gmail.com $\mathrm{e}_{\mathrm{k}}=$ total available capacity for capacity type $k$ such as regular production capacity, overtime production capacity or subcontracting

$\mathrm{d}_{\mathrm{iq}}=$ demand for product $i$ at demand center $q$

$\mathrm{x}_{\mathrm{ijk}}=$ amount of product $i$ produced by process $j$ and capacity type $k$ such as regular production capacity, overtime production capacity or subcontracting

$\mathrm{x}_{\mathrm{ijkq}}=$ amount of product $i$ produced by process $j$ and capacity type $k$ such as regular production capacity, overtime production capacity or subcontracting and shipped to demand center $q$

The first component of the objective function will be:

$\operatorname{Max} \sum \sum \sum \mathrm{R}_{\mathrm{ijk}} \mathrm{X}_{\mathrm{ijk}}$

i j $\mathrm{k}$

that gives the total return on all the products produced by all available different processes and all the available different production capacity types and the goal is to maximize the returns.

The second component of the objective function will be:

$\operatorname{Min} \sum \sum \sum \mathrm{C}_{\mathrm{ijk}} \mathrm{X}_{\mathrm{ijk}}$

i j k

that gives the total production costs on all the products produced by all available different processes and all the available different production capacity types and the goal is to minimize the production costs. The objective here is minimizing the production costs and in order to incorporate this objective into the previous objective function component of maximization of returns we multiply the production cost component by $(-1)$ to get :

$$
\begin{gathered}
\operatorname{Min} \sum \sum \sum \mathrm{C}_{\mathrm{ijk}} \mathrm{X}_{\mathrm{ijk}} \\
\mathrm{i} \mathrm{j} \mathrm{k}
\end{gathered}
$$

and extend the objective function as follows;

$\operatorname{Max}\left(\sum \sum \sum \mathrm{R}_{\mathrm{ijk}} \mathrm{X}_{\mathrm{ijk}}-\sum \sum \sum \mathrm{C}_{\mathrm{ijk}} \mathrm{X}_{\mathrm{ijk}}\right)$
$\mathrm{i} \mathrm{j} \mathrm{k}$
$\mathrm{i} \mathrm{j} \mathrm{k}$

The third component of the objective function will be:

$\operatorname{Min} \sum \sum \sum \sum \mathrm{D}_{\mathrm{ijkq}} \mathrm{x}_{\mathrm{ijkq}}$ 


\section{i j k q}

that gives the total distribution costs on the shipments of all the manufactured items to the demand centers.

In order to incorporate this objective into main maximization objective function we multiply the distribution cost component by $(-1)$ to get :

$$
\begin{array}{cc}
\operatorname{Min} \sum \sum \sum \sum D_{\mathrm{ijkq}} \mathrm{X}_{\mathrm{ijkq}} & =\operatorname{Max}\left(-\sum \sum \sum \sum \mathrm{D}_{\mathrm{ijkq}} \mathrm{X}_{\mathrm{ijkq}}\right) \\
\text { i j k q } & \text { i j k q }
\end{array}
$$

and extend the objective function as follows;

$$
\begin{aligned}
& \operatorname{Max}\left(\sum \sum \sum \mathrm{R}_{\mathrm{ijk}} \mathrm{x}_{\mathrm{ijk}}-\sum \sum \sum \mathrm{C}_{\mathrm{ijk}} \mathrm{x}_{\mathrm{ijk}}-\sum \sum \sum \sum \mathrm{D}_{\mathrm{ijkq}} \mathrm{x}_{\mathrm{jikg}}\right) \\
& \text { i j k i j k i j k q }
\end{aligned}
$$

The objective function is followed by production capacity constraints, transition constraints and distribution/demand related constraints.

The first constraint set:

$\mathrm{mn}$

$$
\begin{aligned}
& \sum \sum \mathrm{x}_{\mathrm{ijk}} \leq \mathrm{e}_{\mathrm{k}} \quad \mathrm{k}=1,2, \ldots, 1 \\
& \mathrm{i} \mathrm{j}
\end{aligned}
$$

ensures that all the products produced by utilizing all the production processes can't exceed the available production capacity type $k$. such as regular production capacity, overtime production capacity or subcontracting.

The second constraint set:

$\mathrm{s}$

$$
\sum \mathrm{x}_{\mathrm{ijkq}}=\mathrm{x}_{\mathrm{ijk}} \quad \mathrm{i}=1,2, \ldots, \mathrm{m} \quad \mathrm{j}=1,2, \ldots, \mathrm{n}
$$

q

$$
\mathrm{k}=1,2, \ldots, 1
$$

ensures that we ship all what we produce and we must produce to the extent that it is possible and profitable to distribute and hence all the production is shipped by utilizing these transition constraints that connect the production and distribution variables.

The third constraint set:

n 1

$\sum \Sigma \mathrm{x}_{\mathrm{ijkq}} \leq \mathrm{d}_{\mathrm{iq}} \quad \mathrm{i}=1,2, \ldots, \mathrm{m} \quad \mathrm{q}=1,2, \ldots, \mathrm{s}$

$$
\mathrm{j} \mathrm{k}
$$

consists of the demand constraints. We use " $\leq$ " format because the demand will be met to the extent that is profitable rather than forcing the model to meet the exact demand at any cost. In certain minimization problems demand constraints are artificially forced to have (=) signs in order to prevent all the variables having zero values; for example, in classical transportation cost minimization model with only supply and demand constraints, the demand constraints are forced to equality constraints even if meeting all the demand at any expense may not necessarily be profitable. However, in the integrated model developed in this paper the transportation component is integrated into the maximization objective function as explained earlier and all of the transportation variables will not be forced to zero even if we use the more suitable " $\leq$ " format for the demand constraints. In the integrated model, the production and transportation issues are treated concurrently and the the losses that would be incurred by not producing and transporting are taken into consideration automatically.

The model in its entirety is presented below:

$$
\begin{array}{ccc}
\operatorname{Max} \sum \sum \sum \mathrm{R}_{\mathrm{ijk}} \mathrm{X}_{\mathrm{ijk}}-\sum \sum \sum \mathrm{C}_{\mathrm{ijk}} \mathrm{X}_{\mathrm{ijk}}-\sum \sum \sum \sum \mathrm{D}_{\mathrm{ijkg}} \mathrm{x}_{\mathrm{ijkg}} \\
\mathrm{i} \mathrm{j} \mathrm{k} \mathrm{j} \mathrm{k} \mathrm{k} & \mathrm{i} \mathrm{j}
\end{array}
$$

st

$$
\begin{aligned}
& \mathrm{mn} \\
& \sum \sum \mathrm{x}_{\mathrm{ijk}} \leq \mathrm{e}_{\mathrm{k}} \quad \mathrm{k}=1,2, \ldots, 1 \\
& \mathrm{i} \mathrm{j} \\
& \mathrm{S} \\
& \Sigma \mathrm{x}_{\mathrm{ijkq}}=\mathrm{x}_{\mathrm{ijk}} \quad \mathrm{i}=1,2, \ldots, \mathrm{m} \quad \mathrm{j}=1,2, \ldots, \mathrm{n} \\
& \text { q } \\
& \mathrm{k}=1,2, \ldots, 1 \\
& \text { n } 1 \\
& \sum \sum \mathrm{x}_{\mathrm{ijkq}} \leq \mathrm{d}_{\mathrm{iq}} \quad \mathrm{i}=1,2, \ldots, \mathrm{m} \quad \mathrm{q}=1,2, \ldots, \mathrm{s} \\
& \mathrm{j} \mathrm{k}
\end{aligned}
$$

\section{CONCLUSION}

In real life operating situations, we daily face the questions as to how much should we produce and how should we produce in order to optimize the resources. This paper addresses the issues of which products should be produced and in what quantity, by what production process should they be produced and by what type of production capacity. This integrated model is capable of answering such multiple questions as well as determining the optimal distribution routes concurrently. Therefore, such an optimization model can find use in practice and be very beneficial in certain industrial and agricultural applications.

\section{REFERENCES}

[1] S Cokelez \& J Burns, Distribution Systems-Warehouse Location and Capacity, Omega, The International Journal of Management Science,, Vol. 17, No. 1, pp. 45-51. 